\title{
O Brasil de Paul Muldoon
}

Viviane Carvalho da Annunciação

Em razão de sua ironia sagaz e de seu exímio trabalho com as formas poéticas, o poeta Paul Muldoon é uma das vozes poéticas mais respeitadas no cenário intelectual da Irlanda do Norte. Nativo do Condado de Armagh, região dividida entre raízes culturais católicas e protestantes, o poeta faz do sarcasmo uma poderosa arma para representar a cultura híbrida de seu lugar de origem. Apolítico e apartidário, sua obra, além de oferecer um viés alternativo, traz um importante dado na representação da cultura local: o diálogo intercultural. Oriundo de uma geração que abarca grandes nomes, como o prêmio Nobel Seamus Heaney e o aclamado Derek Mahon, Paul Muldoon reflete sobre o imaginário e as mitologias latino-americanas. Dentre os produtos dessa investigação estão os volumes Meeting The British (1987), Madoc: A Mystery (1990) e The Annals of Chile (1994). Entretanto, imagens, ritmos e sonoridades latino-americanas já ressoavam em seu trabalho no volume $W$ by Brownlee Left (1980). Dentre as localidades representadas, uma das preferidas é o Brasil. Este país, cuja paisagem geográfica e cultural já inspirou grandes nomes poéticos como Elizabeth Bishop e, mais recentemente, o irlandês Paul Durcan, torna-se, na voz de Muldoon, uma metáfora para seu deslocamento geográfico e cultural.

Depois de passar as décadas de 1970 e 1980 trabalhando na BBC (British Broadcasting Corporation) de Belfast, Muldoon muda para os Estados Unidos, onde hoje é professor da Princeton University, diretor da Cátedra Peter B. Lewis, no Centro para as Artes da mesma universidade e editor de poesia da revista The New Yorker. A qualidade de seu trabalho foi exaltada pelas comissões julgadoras de diversos prêmios importantes, dentre os quais o Prêmio de poesia T. S. Eliot, em 1994, o Prêmio de Poesia da Revista Times de 1997, o Pulitzer Prize de 2003 e o Prêmio Europeu de Poesia em 2006. Além de exibir uma profunda reflexão sobre a herança poética em língua inglesa, a poesia de Muldoon ultrapassa o limite formal e exibe 
o deslocamento subjetivo de um poeta cuja língua é perpassada por tradições irlandesas e britânicas. O dado intercultural surge no trato com culturas ditas "exóticas" ou "diferentes". Porém, em seu retrato do Brasil, Muldoon não exibe tons de superioridade ou julgamento de valores: o país do poeta é parte constitutiva de seu trabalho artístico. Não se trata de um lugar onde o poeta passou um período e produziu um livro de poemas (Muldoon nunca esteve em terras brasileiras), mas de um local que o auxilia a configurar sua identidade artística. Além do mais, ajuda-o a compreender o significado de escrever poesia no mundo contemporâneo. Os temas abordados pelos poemas que retratam o Brasil são imigração, descoberta sexual e reconfiguração histórica. Esses tópicos são retratados mais especificamente nos poemas: "Immrama" Why Brownlee Left (1980), "The Lass of Aughrim" (Meeting the British, 1987) and "Brazil" (The Annals of Chile, 1998).

A tradução aqui apresentada visa mostrar ao leitor brasileiro a representação de seu país feita por um poeta norte-irlandês. Entretanto, cabe ressaltar que esse retrato é mais do que um olhar alienado. Ele é, na verdade, parte constituinte de uma psique artística que tem o interculturalismo como alicerce de sua lírica. Todos os poemas sobre o Brasil são variações de sonetos narrativos. Sendo assim, expressam, duplamente, a coloquialidade da fala prosaica e a musicalidade do verso. Além do mais, as experimentações artísticas, bem como a métrica e o estranhamento das imagens, envolvem a experiência pessoal em uma rede de significados globais. $\mathrm{O}$ ethos produzido por tais relações é um espaço subjetivo de confluências, pois a poética torna-se um espaço criativo onde escritor e leitor configuram suas identidades coletivas e específicas.

No primeiro poema traduzido, "Immrama", o poeta aborda o tema da descoberta de suas raízes familiares em um ambiente estranho. Vale ressaltar que "Immrama" é uma palavra irlandesa que, nas lendas antigas, significa a viagem de um herói para terras distantes. No poema, a viagem feita por Muldoon é até as favelas brasileiras, onde ele observa seu pai, que imigrou para a América do Sul em busca de melhores condições de vida. Porém, sua tentativa foi frustrada e o pai não atinge sucesso econômico, tendo que morar em uma região igualmente pobre. Por meio da narrativa do poema, o leitor estabelece uma conexão entre a vida humilde dos camponeses irlandeses e dos moradores dos cortiços e das favelas do Brasil. Entretanto, nos últimos versos do poema, Muldoon sugere uma imagem de esperança, pois foca nos seus irmãos que dormem debaixo do mosquiteiro. Tal imagem contrasta com as duras condições de trabalho descritas nos versos anteriores do poema. Portanto, em "Immrama" a descoberta de suas raízes no Brasil, embora evoque pobreza, também sugere uma velada esperança no 
sono apaziguador das crianças. Na tradução, mantém-se o aspecto coloquial e prosaico do verso.

\section{Immrama}

I, too, have trailed my father's spirit

From the mud-walled cabin behind the mountain

Where he was born and bred,

TB and scarlatina,

The farm where he was first hired out,

To Wigan to Crewe junction

A building-site from which he disappeared

And took passage, almost, for Argentina

The mountain is coming down with hazel,

The building-site a slum

While he has gone no further than Brazil

That's him on the verandah, drinking rum

With a man who might be a Nazi,

His children asleep under their mosquito-nets.

\section{Immrama}

Eu também segui o espírito do meu pai

Da choupana de barro atrás da montanha,

Onde ele nasceu e cresceu,

Tuberculose e escarlatina,

Da primeira fazenda onde ele foi contratado,

Até Wigan e o cruzamento de Crewe

Do canteiro de obras de onde ele desapareceu

e seguiu em direção quase que à Argentina

A montanha adoece com a cor das castanhas

O canteiro de obras, um cortiço

Enquanto ele não conseguiu ir além do Brasil, 
É ele na varanda, bebendo rum

Com um homem que poderia ser um nazista

Seus filhos dormem sob os mosquiteiros.

No segundo poema traduzido, "Brazil", o poeta descreve seu despertar sexual, ainda garoto, enquanto observa sua mãe pronunciar o morfema $n h$, na palavra champignon, em português. No poema, a sonoridade desconhecida desencadeia sua descoberta interior e amadurecimento, visto que o desejo é acompanhado pela culpa. Na relação mãe e filho há um forte elemento do "complexo de Édipo", que é potencializado ao longo do poema. Na tradução, tentamos deixar claro esse elemento ambíguo de prazer e culpa que o garoto tem ao observar a sua mãe.

A maior dificuldade de tradução do poema envolve os termos "widdershins" and "deasil". Enquanto no poema optamos pela tradução "sentido anti-horário" e "sentido horário", é essencial ressaltar que tais correspondências não são suficientes para expressar o significado do poema. A palavra "widdershins" tem origem na baixa Idade Média e significa ir contra a direção do sol, atitude que poderia trazer má sorte para os povos antigos das Ilhas Britânicas. Na mitologia de Yorkshire, acreditava-se que o ato de caminhar no sentido horário, ao redor de cogumelos, poderia abrir um portal entre o mundo humano e o mundo das fadas (ELLIS, 1994, p. 223). Igualmente, a palavra "deasil" tem origem no gaélico antigo e significa caminhar no sentido do sol. Contudo, o termo também é válido para os rituais druidas que envolviam danças em torno de objetos inanimados ou pessoas (QUINION, Web 2013). A dança no sentido horário evoca qualidades positivas.

Desta maneira, a dualidade desejo e repressão é representada pelo vocábulo religioso incisivamente utilizado em "Brazil". A escolha do título pode também provir da visão do Brasil como um país onde a repressão sexual não é tão perturbadora como a da Irlanda do Norte e da República da Irlanda. Portanto, enquanto a imagem do Brasil representa liberdade e sensualidade, a identidade irlandesa, identificada na estranheza dos termos arcaicos, significa o seu oposto, proibição e repressão.

\section{Brazil}

When my mother snapped open her flimsy parasol it was Brazil: if not Brazil, 
then Uruguay,

One nipple darkening her smock

My shame-faced Tantum Ergo

Struggling through the thurified smoke.

Later that afternoon would find

me hunched over the font

as she rinsed my hair. Her towel-turban.

Her terrapin

Comb scuttling under the faucet

I stood there in the string vest

and shorts while she repeated, Champi...?

Champi...? Champi...? Then,

The bracelet of shampoo

about the bone, her triumphant 'Champiñon'.

If not Uruguay, then Equador:

It must be somewhere near the equator

given how water

plunged headlong into water

when she pulled the plug.

So much for the obliq-

uity of leaving What a boy should know

under my pillow: now vagina and vas 
deferens made a holy show

of themselves. 'There is inherent vice

in everything' as O'Higgans

would proclaim. It was O’Higgans who duly

had the terms 'widdershins'

and 'deasil' expunged from the Annals of Chile.

\section{Brasil}

Quando minha mãe abriu com um solavanco sua fraca sombrinha: Brasil: se não Brasil,

então Uruguai,

Um mamilo escurecia sua blusa

Minha face enrubescida Tantum Ergo

Sofrendo sob a fumaça do turíbulo

Mais tarde naquela noite iriam me encontrar

debruçado sob a pia

enquanto ela lavava meu cabelo. Sua toalha-turbante.

Seu pente

de tartaruga rastejando na torneira

eu fiquei lá, vestido apenas com uma segunda pele

e shorts enquanto ela repetia, Champi...?

Champi...? Champi...? Então,

A pulseira de shampoo

no seu pulso, seu triunfante champignon. 
Senão Uruguai, então Equador:

só pode ser algum lugar perto do Equador

já que a água

caía retilínea na água

quando ela puxou o tampão.

Tudo isso para obliqui-

dade de deixar "O que um garoto deve saber"

debaixo do meu travesseiro: agora a vagina e o canal

deferente apareciam em

todo seu esplendor: "há um vício intrínseco

em tudo", como O’Higgans

proclamaria. Foi O’Higgans que legalmente

removeu os termos "sentido anti-horário"

e "sentido-horário" dos Anais do Chile.

O terceiro poema "A garota de Aughrim" também estabelece conexões entre o Brasil e Irlanda por meio das expedições ultramarinas. "A Garota de Aughrim" é uma canção popular muito conhecida na Irlanda, e que foi imortalizada por James Joyce no conto "The Dead". No conto, a canção favorece a revelação da personagem Gretta, cuja memória de seu amor de infância faz com que ela reconheça o vazio de seu casamento. No poema, há uma revelação: o poeta ouve um indiozinho tocando as notas da canção para encantar os peixes do rio. Tais conexões, embora simples, remontam aos missionários irlandeses que vieram à Amazônia evangelizar os nativos. De uma forma obscura, essa evocação pode ser uma referência a Roger Casement, revolucionário irlandês que lutou contra os maus tratos da população nativa na região. A tradução do poema busca reproduzir a métrica curta e ritmada, e, ao mesmo tempo, coloquial e prosaica. 


\section{The lass of Aughrim}

On a tributary of the Amazon

an Indian boy

steps out of the forest

and strikes up on a flute.

Imagine my delight

when we cut the outboard motor

and I recognize the strains

of The Lass of Aughrim.

'He hopes', Jesus explains,

'to charm

fish from water

on what was the tibia

of a priest

from a long abandoned Mission'.

\section{A garota de Aughrim}

Em um afluente do Amazonas

um indiozinho

salta da floresta

e sapeca uma flauta.

Imagine o meu deleite

quando desligamos o motor

e eu reconheci as notas

da Garota de Aughrim.

“Ele espera", explica Jesus,

"encantar

os peixes do rio 
com o que era a tíbia

de um padre

em uma longa e abandonada Missão".

O objetivo das traduções não é fornecer uma análise completa do olhar de Muldoon sobre as terras brasileiras, mas oferecer uma visão geral de como o Brasil é representado em seus poemas. $\mathrm{O}$ aspecto crucial dessa representação é a falta do julgamento de valores: Brasil e Irlanda são tratados igualmente, como lugares que auxiliam o poeta a delinear o seu percurso artístico. Ambas as tradições locais - e até mesmo pobrezas locais - servem como parâmetro para a experimentação poética. Esse dado é revelador, pois mesmo nunca estando no Brasil, o poeta consegue um retrato verossímil e próximo à realidade. Nesse sentido, a obra de Muldoon é um campo aberto para investigações e merece a atenção da crítica literária e cultural brasileira.

\section{Referências}

ELLIS, Peter. Dictionary of Celtic Mythology. USA: Oxford University Press, 1994.

MULDOON, Paul. Why Brownlee Left. London: Faber \& Faber, 1980.

Meeting the British. London: Faber \& Faber, 1987.

The Annals of Chile. London: Faber \& Faber, 1998.

To Ireland, I. Oxford: Oxford University Press, 2000.

QUINION, Michael. "Deasil”. Página eletrônica. http:/ / wmw.worldwidewords.org/ weirdwords/ ww-dea1.htm. Consulta realizada em 29 de janeiro de 2013. 